\title{
Research on Temperature Distribution in Wellbore of Deep Well Drilling
}

\section{Boyi Xia}

Engineering Technology Research Institute, CNPC Greatwall Drilling Engineering Comapany Limited, Liaoning, China Email: xiaby_gwdc@126.com

How to cite this paper: Xia, B.Y. (2021) Research on Temperature Distribution in Wellbore of Deep Well Drilling. Open Journal of Applied Sciences, 11, 1269-1276. https://doi.org/10.4236/ojapps.2021.1112096

Received: November 15, 2021

Accepted: December 13, 2021

Published: December 16, 2021

Copyright $\odot 2021$ by author(s) and Scientific Research Publishing Inc. This work is licensed under the Creative Commons Attribution International License (CC BY 4.0).

http://creativecommons.org/licenses/by/4.0/

\begin{abstract}
The wellbore temperature has an important effect on design and drilling of deep well. Based on energy conservation equations and actual drilling data of one deep well, the wellbore temperature distribution was simulated and the influence of different parameters on the wellbore temperature was revealed using the software of Hydraulics Analysis System. The results show that, while drilling, the mud temperature in wellbore gradually decreases from the formation temperature to the stable temperature, and it is higher than the mud inlet temperature on ground, the annular temperature is higher than the temperature in drill string, and the bottom hole temperature is higher than the ground temperature. The effect of geothermal gradient on wellbore temperature is great, while the mud density is negligible. The bottom hole temperature increases with the increase of mud inlet temperature, geothermal gradient, mud thermal conductivity and decrease of mud flow rate, mud specific heat and mud density.
\end{abstract}

\section{Keywords}

Deep Well, Drilling, Temperature Distribution, HAS

\section{Introduction}

With the increase of world energy demand and the development of petroleum industry, deep and ultra-deep wells have become an important way of oil-gas development [1]. In our country, deep and ultra-deep wells with depths of more than $4500 \mathrm{~m}$ to $7000 \mathrm{~m}$ are common in Xinjiang and Sichuan, especially in Sichuan and Chongqing, where there are a large number of deep and ultra-deep gas wells in the HTHP (high temperature and high pressure) gas fields [2]. Generally speaking, the deeper the well, the higher the downhole pressure and temperature, and the greater the technical difficulties. In the past, deep exploration 
focused more on finding oil, and the geothermal gradient was low. In the future, more attention will be paid to deep gas exploration, and the problem of high temperature and high pressure will become prominent. The high temperature and high pressure will affect the mud property in the wellbore [3] [4], which makes the bottom hole pressure calculation have large errors and easily cause drilling accidents. Meanwhile, the excessive temperature also restricts the use of many downhole tools.

In 1962, Ramey proposed the classical method of predicting wellbore fluid temperature distribution [5]. He took the fluid temperature as a function of well depth and time, deduced the calculation formula of wellbore temperature and put forward the concept of comprehensive heat transfer coefficient. In 1967, Willhite gave the classical formula for calculating the total heat transfer coefficient [6]. Later, many scholars proposed new calculation models of wellbore temperature based on Ramey method [7] [8] [9]. In China, in 1996, aiming to solve the problem of heavy oil thermal recovery, Li Zifeng established a prediction model of well temperature distribution in the process of circulation [10], and solved the model by finite volume method. Other scholars subsequently developed some similar or improved models [11] [12]. These studies have shown that the temperature in the wellbore is not exactly the same as the geothermal field and is a dynamic process that requires a dedicated model for calculation. For this reason, the HAS (Hydraulics Analysis System) software developed by Chongqing University of Science and Technology was imported and the temperature distribution in wellbore of deep well drilling was analyzed. The analysis result can be useful for the design of deep well drilling.

\section{Model Development}

\subsection{Model Equations}

The well structure and heat transfer diagram in deep well is shown in Figure 1.

The energy conservation equations of various media in the wellbore system [11], such as drilling fluid, drill string, annulus and formation, can be expressed as follows:

$$
\begin{gathered}
\frac{\partial(\rho c T)}{\partial t}+\frac{\partial(\rho c v T)}{\partial z}=\frac{1}{r} \frac{\partial}{\partial r}\left(\frac{r k}{c} \frac{\partial(c T)}{\partial r}\right)+\frac{\partial}{\partial z}\left(\frac{k}{c} \frac{\partial(c T)}{\partial z}\right)+S \\
S=\rho T \frac{d c}{d t}-\nabla\left(\frac{k}{c} T \nabla c\right)+q_{f}+q_{t}
\end{gathered}
$$

In the above equations, $t$ is time, $z$ is the axial position along wellbore, $r$ is the radial position in borehole, $T$ is the temperature in drill string or annular, $\rho$ is the density of drilling fluid, $c$ is the specific heat of drilling fluid, $v$ is the drilling fluid flow velocity, $T$ is the temperature of drilling fluid, $k$ is the convective heat transfer coefficient, $q_{f}$ is the heat generated by mechanical energy loss of rotary drilling tool, pressure drop of bit nozzle or fluid circulating pressure loss in per volume, $q_{t}$ is the heat transfer quantity in per volume between the tube 


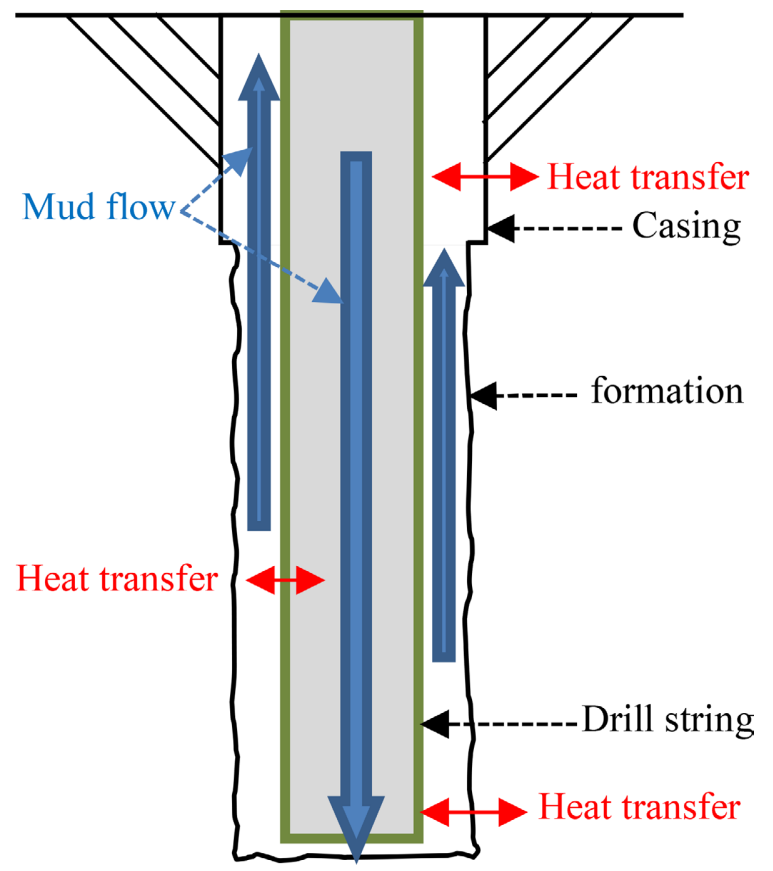

Figure 1. Temperature transfer in deep well.

string and the annular space, or between the annular space and the formation.

\subsection{Model Solver}

Apparently the temperature distribution is related not only with heat conduction but also with fluid pressure transfer. Due to the complexity the model cannot be calculated directly. HAS solves the equations to get the temperature distribution in deep well using full implicit difference and Gauss-Seidel iteration methods.

To calculate borehole pressure loss accurately, HAS uses different mud rheological modes (powerlaw, binham, carson and $\mathrm{H}-\mathrm{B}$ ) and a variety of rheological parameter calculation and optimization methods to descript the mud rheological properties. The effects of drill pipe rotation, eccentricity, joints and the downhole motor pressure drop are also taken into account as well as the different hole cleaning conditions, which are the flow with single-phase fluid, the flow with full suspension of cuttings, the flow with general cleaning condition and the flow with poor cleaning condition in the calculation of borehole pressure loss, based on the advanced three-layer cuttings dynamic transport theoretical model of ERW, empirical calculation model of cuttings transport in whole section of ERW under multiple working conditions [13].

Coupling the above model of pressure loss and calculation model [14] of heat transfer in deep well and ultra-deep well [15], HAS can calculate and analyze the wellbore temperature distribution during drilling whether to consider the effects of temperature and pressure on mud performance, including mud density and mud rheological properties. Thus, the calculation results of wellbore pressure can be corrected to improve the accuracy of calculation and design of deep wells, HTHP wells and deep water wells. The calculation results are very accurate. A 
large number of field applications show that the calculation error can be controlled within $5 \%$.

Based on these models, HAS can be also used for hydraulics design before drilling, hydraulics monitoring during drilling and hydraulics analysis and optimization before or after drilling. It can be used for hydraulics analysis, monitoring, design and optimization of complex structural wells drilling such as conventional directional wells, horizontal wells, sidetrack wells, small wellbore wells, deep wells, ultra-deep wells, HTHP wells, deepwater wells, etc.

The temperature analysis module of HAS is shown in Figure 2.

\section{Case Study}

\subsection{Basic Data}

A vertical deep well of $7000 \mathrm{~m}$ was drilled with $\Phi 215.9 \mathrm{~mm}$ bit, $\Phi 139 \mathrm{~mm}$ drill pipe. The oil-based mud density was $1.75 \mathrm{~g} / \mathrm{cm}^{3}$, mud inlet temperature was $27^{\circ} \mathrm{C}$, mud flow rate was $30 \mathrm{~L} / \mathrm{s}$, nozzle combination was $\Phi 22 \mathrm{~mm}+\Phi 22 \mathrm{~mm}+$ $\Phi 33 \mathrm{~mm}$, the specific heat of mud, steel and formation were 1675, 400 and 837 $\mathrm{J} /\left(\mathrm{Kg} \cdot{ }^{\circ} \mathrm{C}\right)$ respectively, and the thermal conductivity was $1.73,44$ and $2.25 \mathrm{~W} /\left(\mathrm{m} \cdot{ }^{\circ} \mathrm{C}\right)$ respectively, the geothermal gradient was $3^{\circ} \mathrm{C} / 100 \mathrm{~m}$.

\subsection{Calculation Result}

Figure 3 is the variation of temperature distribution in drill string and in annular



Figure 2. The temperature analysis module of HAS. 

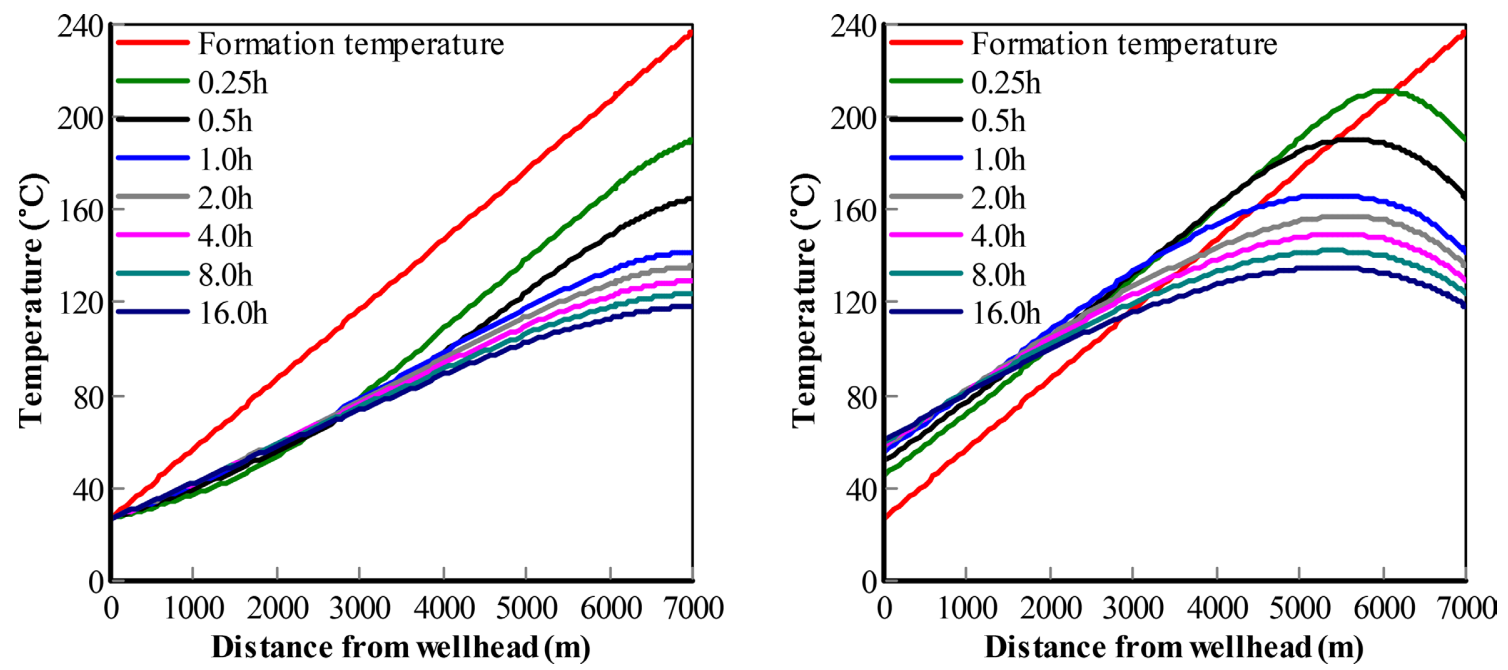

Figure 3. Temperature variation in drill string (left) and annular (right).

with time when drilling to $7000 \mathrm{~m}$. It can be seen from the figures that with the progress of drilling, the mud temperature in wellbore gradually decreases from the geothermal temperature to a stable temperature. After 16 hours, the temperature change begins to slow down whether in annular or drill string. The bottom hole temperature is about $118^{\circ} \mathrm{C}$, which is $91^{\circ} \mathrm{C}$ higher than the mud inlet temperature, and the annular temperature is greater than the temperature in drill string. If the geothermal gradient is higher, for example $5^{\circ} \mathrm{C} / 100 \mathrm{~m}$ in Southwest oil and gas field in China, the bottom hole temperature will become a big problem for drilling.

\section{Discussion}

In general, the temperature in annular is always higher than drill string. Therefore, the sensitivity analysis is performed with the annular temperature distribution when drilling to $7000 \mathrm{~m}$ after 16 hours. The factors affecting the temperature distribution include mud inlet temperature (tin), geothermal gradient $(t g)$, mud specific heat $(C f)$, mud thermal conductivity $(K f)$, mud density $(\rho f)$ and mud flow rate $(Q f)$. The influence of each factor on the annulus temperature is shown in Figures 4-6. It can be seen from these figures that the bottom hole temperature increases with the increase of mud inlet temperature, geothermal gradient and mud thermal conductivity, and decreases with the increase of mud flow rate, mud specific heat and mud density. Geothermal gradient and mud specific heat have a greater impact on the annulus temperature field than mud thermal conductivity, mud inlet temperature and mud flow rate, while mud density has negligible impact.

\section{Conclusions}

1) Based on the theory of fluid mechanics and heat transfer, considering the characteristics of deep well drilling, a wellbore temperature model was proposed in drilling of deep wells. Using full implicit difference and Gauss-Seidel iteration 

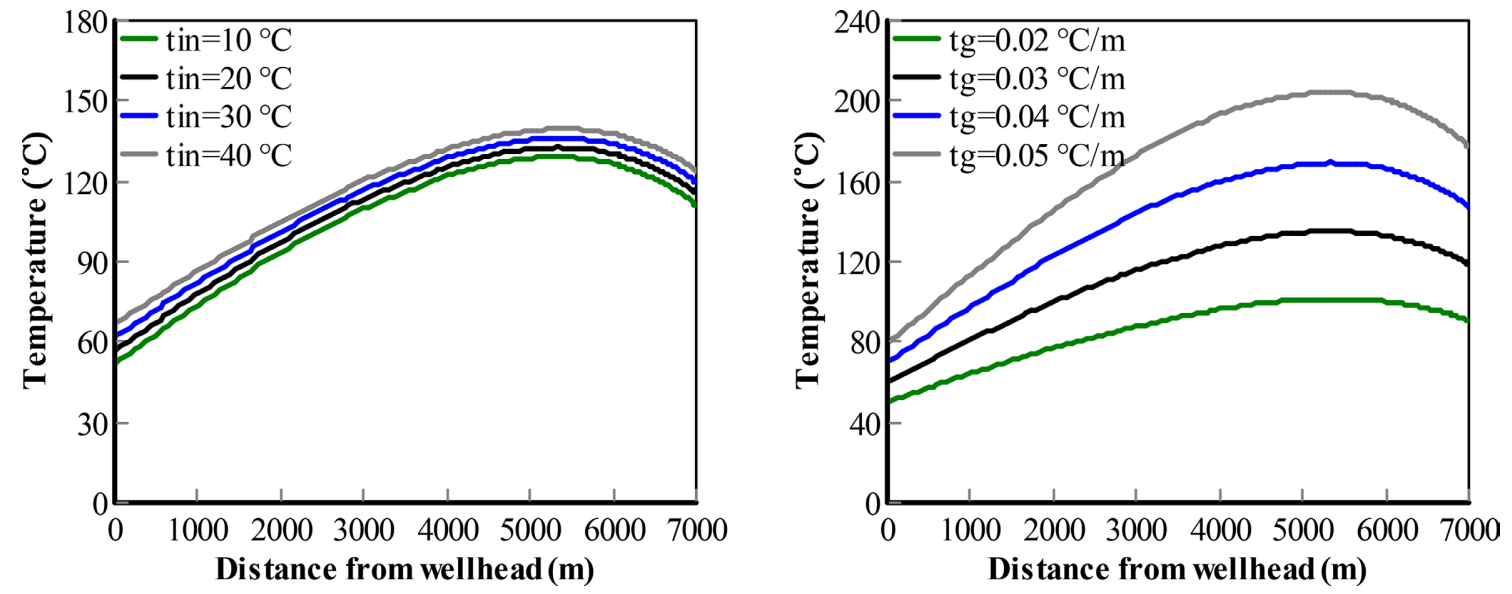

Figure 4. Annular temperature vs. mud inlet temperature (left) and geothermal gradient (right).
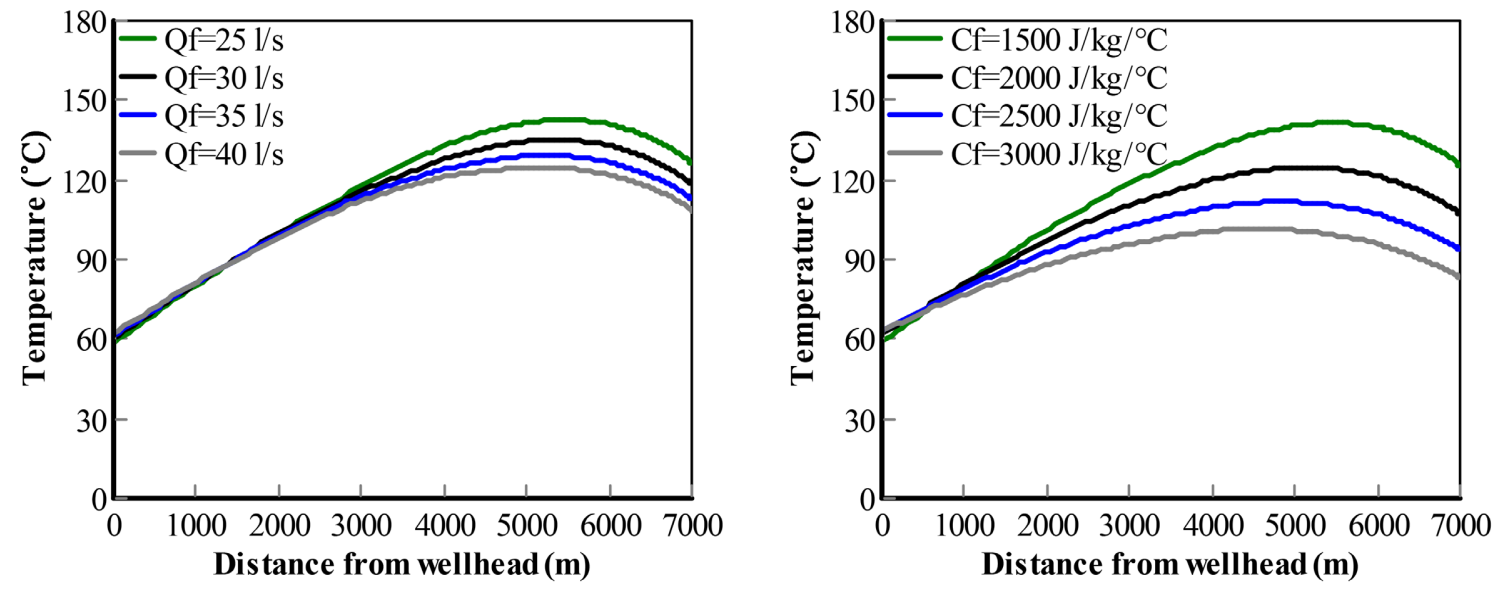

Figure 5. Annular temperature vs. mud flow rate (left) and mud specific heat (right).
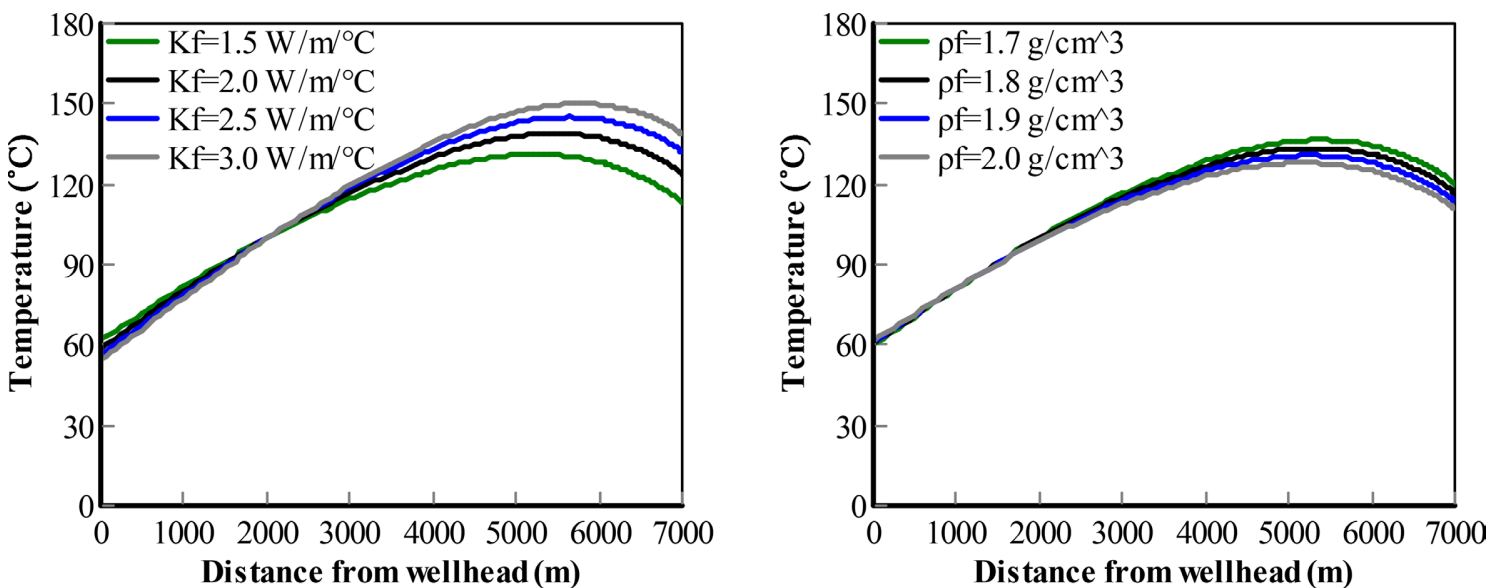

Figure 6. Annular temperature vs. mud thermal conductivity (left) and mud density (right).

methods, the model was solved and the distribution of wellbore temperature can be calculated and analyzed.

2) With the progress of drilling, the mud temperature in wellbore gradually decreases from the geothermal temperature to a stable temperature. The mud 
temperature in wellbore is higher than the mud inlet temperature on the ground, the annulus temperature is higher than the temperature in the drill string, and the bottom hole temperature is higher than the ground temperature.

3) The factors affecting the temperature field include mud inlet temperature, geothermal gradient, mud specific heat, mud thermal conductivity, mud density and mud flow rate, etc. The bottom hole temperature increases with the increase of mud inlet temperature, geothermal gradient and mud thermal conductivity, and decreases with the increase of mud flow rate, mud specific heat and mud density.

4) Geothermal gradient and mud specific heat have a greater impact on the annulus temperature field than mud thermal conductivity, mud inlet temperature and mud flow rate, while mud density has negligible impact.

\section{Conflicts of Interest}

The author declares no conflicts of interest regarding the publication of this paper.

\section{References}

[1] Yan, G.Q. and Zhang, J.C. (2013) Status and Proposal of the Sinopec Ultra-Deep Drilling Technology. Petroleum Drilling Techniques, 41, 6. (In Chinese)

[2] Wu, X.Z. (2008) Drilling Technology in Deep and Ultradeep Gas Wells in the Sichuan and Chongqing Gas Fields. Natural Gas Industry, 28, 9-13. (In Chinese)

[3] Wang, H.G. and Liu, Y.S. (2000) Effect of Temperature and Pressure on Drilling Fluid Density in Hthp Wells. Drilling \& Production Technology, 23, 56-60. (In Chinese)

[4] Zhao, S.Y., Yan, J.N., Wang, L.G., et al. (2009) Prediction Model of Equivalent Drilling Fluid Density at High Temperature and High Pressure. Petroleum Drilling Techniques, 3, 48-52. (In Chinese)

[5] Ramey, H.J. (1962) Wellbore Heat Transmission. Journal of Petroleum Technology, 14, 427-435. https://doi.org/10.2118/96-PA

[6] Willhite, G.P. (1967) Over-All Heat Transfer Coefficients in Stream and Hot Water Injection Wells. Journal of Petroleum Technology, 19,607-615.

https://doi.org/10.2118/1449-PA

[7] Thompson, M. and Burgess, T.M. (1985) The Prediction of Interpretation of Downhole Mud Temperature While Drilling. The 60 th Annual Technical Conference and Exhibition of the Society of Petroleum Engineers, Las Vegas, September 1985, SPE14180-MS. https://doi.org/10.2118/14180-MS

[8] Hasan, A.R., Kabir, C.S., Ameen, M.M., et al. (1996) A Fluid Circulating Temperature Model for Workover Operations. Society of Petroleum Engineers Journal, 1, 133-144. https://doi.org/10.2118/27848-PA

[9] Romero, J. and Touboul, E. (1998) Temperature Prediction for Deepwater Wells,A Field Validated Methodology. The 1997 SPE Annual Technical Conference and EXhibition, New Orleans, September 1998, SPE-49056-MS. https://doi.org/10.2118/49056-MS

[10] Li, Z.F. (1996) Mathematical Model for Temperature Field of Wellbore and Formation. Oil Drilling \& Production Technology, 18, 54-58. (In Chinese)

[11] Zhong, B. (1999) A New Model to Predict Temperature Distribution in a Wellbore 
While Drilling. Journal of Southwest Petroleum Institute (Edition of Natural Science), 21, 53-56. (In Chinese)

[12] He, S.M., Yin, C., Xu, B.H., et al. (2002) Mathematical Model of Determining Wellbore Circulating Temperature in Cementing and Drilling Processes. Natural Gas Industry, 22, 42-45. (In Chinese)

[13] Guo, X.L., Wang, Z.M. and Long, Z.H. (2010) Study on Three-Layer Unsteady Model of Cuttings Transport for Extended-Reach Well. Journal of Petroleum Science and Engineering, 73,171-180. https://doi.org/10.1016/j.petrol.2010.05.020

[14] Guo, X.L. and Wang, Z.M. (2008) Precise Method of Calculating Circulating Pressure Loss in Extended Reach Wells. Journal of Oil and Gas Technology, 30, 99-102. (In Chinese)

[15] Guo, X.L., Long, Z.H., Wang, Z.M., et al. (2014) Study on Coupling Law of Wellbore Temperature and Pressure Fields in Deep Water Drilling with Riser System. China Offshore Oil and Gas, 26, 66-69. (In Chinese) 